\title{
Adult-to-adult living donor liver transplantation: Operative techniques to optimize the recipient's outcome
}

\author{
Peng Soon Koh, \\ See Ching Chan ${ }^{1}$
}

\author{
Department of Surgery, Faculty of Medicine, University of Malaya, Kuala Lumpur, Malaysia, \\ ${ }^{1}$ Department of Surgery, The University of Hong Kong, Hong Kong, SAR, China \\ Address for correspondence: \\ Prof. See Ching Chan, Department of Surgery, The University of Hong Kong, Queen Mary Hospital, \\ Pok Fu Lam Road, Hong Kong, SAR, China. E-mail: seechingchan@gmail.com
}

\begin{abstract}
Adult-to-adult living donor liver transplantation (LDLT) is widely accepted today with good outcomes and safety reported worldwide for both donor and recipient. Nonetheless, it remained a highly demanding technical and complex surgery if undertaken. The last two decades have seen an increased in adult-to-adult LDLT following our first report of right lobe LDLT in overcoming graft size limitation in adults. In this article, we discussed the operative techniques and challenges of adult right lobe LDLT incorporating the middle hepatic vein, which is practiced in our center for the recipient operation. The various issues and challenges faced by the transplant surgeon in ensuring good recipient outcome are explored and discussed here as well. Hence, it is important to understand that a successful recipient operation is dependent of multifactorial events starting at the preoperative stage of planning, understanding the intraoperative technical challenges and the physiology of flow modulation that goes hand-in-hand with the operation. Therefore, one needs to arm oneself with all the possible knowledge in overcoming these technical challenges and the ability to be flexible and adaptable during LDLT by tailoring the needs of each patient individually.
\end{abstract}

Key words: Living donor liver transplantation, operative techniques, right lobe liver transplantation

\section{INTRODUCTION}

Following the first orthotopic liver transplantation (LT) described by Starzl in 1963, LT has undergone a series of evolution over the five decades and together with improved perioperative care, surgical, and medical therapies have seen marked reduction in mortality and morbidity rates. ${ }^{[1,2]}$

The scarcity of deceased donor liver graft, especially in Asia have led to the pursuit of living donor LT (LDLT) in this region as an alternative to treatment of various liver diseases such as acute liver failure, liver cirrhosis, hepatocellular carcinoma, metabolic liver diseases, and so forth. ${ }^{[3]}$

\begin{tabular}{|l|l|}
\hline \multicolumn{2}{|c|}{ Access this article online } \\
\hline Quick Response Code: & Website: \\
\hline & www.jnsbm.org \\
\cline { 2 - 3 } & \\
\hline
\end{tabular}

Nonetheless, embarking on LDLT has its fair share of concern, as great importance is placed on donor safety and hence, justification for LDLT should at least ensure acceptable donor morbidity, a voluntary donor and good outcomes in recipient. ${ }^{[4,5]}$ At present, donor mortality is estimated to be $0.1 \%$ for left lobe donors and up to $0.5 \%$ for right lobe donors with expected morbidity around $20-30 \% .^{[6-8]}$

Being the only liver transplant center in Hong Kong and one of the leading liver transplant centers in Asia, our experience with LT began in the early 90s and have seen cases of LT exponentially increased over the years due

This is an open access article distributed under the terms of the Creative Commons Attribution-NonCommercial-ShareAlike 3.0 License, which allows others to remix, tweak, and build upon the work non-commercially, as long as the author is credited and the new creations are licensed under the identical terms.

For reprints contact: reprints@medknow.com

How to cite this article: Koh PS, Chan SC. Adult-to-adult living donor liver transplantation: Operative techniques to optimize the recipient's outcome. J Nat Sc Biol Med 2017;8:4-10. 
to demand with majority of cases being LDLT. ${ }^{[8]}$ It is here the first right liver adult-to-adult LT was performed in May 1996 in order to overcome graft size limitation often faced with adult-to-adult LDLT. ${ }^{[9]}$ Since then, right liver adult-to-adult LDLT have been adopted in various centers. $^{[10,11]}$

Here, we share our two decades of experience in right lobe adult-to-adult LDLT and devised various important factors to be taken into consideration in ensuring good recipient outcome.

\section{INTRAOPERATIVE TECHNIQUES}

\section{Starting preoperatively}

It cannot be more understated that a good recipient outcome starts before the patient is placed on the operating table. As LDLT is a highly complex surgical operation, a thorough preoperative preparation of the recipient is mandatory to ensure good postoperative outcome and future compliance to treatment. A multidisciplinary team involving surgeons, physicians, anesthetists, clinical psychologist, transplant coordinator, and counselors are vital at the beginning of work-up.

\section{Psychosocial aspects}

A major aspect in the beginning of this process involves the psychosocial evaluation and preparation of both donor (will not be discussed here) and recipient. Establishing a good understanding and trust between patient and the transplant team would be the first step toward a successful recipient outcome. Goals are set between patient and family members and expectations, worries and beliefs are addressed. Postoperative recovery, stress management, psychosocial problems, rehabilitation, and future lifestyle are also discussed at this stage. ${ }^{[12-15]}$ Early strategy such as this is important in promoting a healthy psychological and physical well-being of the recipient as well as motivation and treatment compliance after transplantation. ${ }^{[16]}$

\section{Graft size}

In adult-to-adult LDLT, the main issue faced is graft size limitation, especially when left lobe graft is used. Hence, to overcome this, a right liver graft is often chosen to overcome a small partial graft as recipients can developed small-for-size syndrome (SFSS) where a partial graft is considered too small to meet functional demands, which may ultimately lead to graft failure and death. ${ }^{[9,17]}$ Generally, small-for-size graft is defined as graft-weight-to-recipient-weight (GRWR) ratio of $<0.8 \%{ }^{[18]}$ Recently, Lee et al. have shown that even a GRWR up to $0.7 \%$ is safe and favorable in LDLT in selected cases. ${ }^{[19]}$
However, in our practice, the use of graft estimation using the graft volume (GV) or GW to estimated standard liver volume (ESLV) is often used as it gives a better estimation in selection of donor graft for our recipients and preventing SFSS. ${ }^{[20]}$ A GV $/$ ESLV of $<35 \%$ or GW $/$ ESLV of $<30 \%$ would be considered small for size.

This may aid us in estimation of adequate GV or weight for the recipient, but functionally, each recipient may still need to be individualized as those with portal hypertension may require a larger graft size. ${ }^{[21]}$ Prevention of SFSS may also require good venous drainage or outflow and avoidance of hypo- or hyper-perfusion of portal inflow as it may have deleterious effect on the graft. ${ }^{[22-24]}$ We will further elucidate in overcoming these issues of graft outflow and inflow strategy in our intra-operative techniques for adult recipient LDLT below.

\section{Techniques in procuring donor graft}

In this article, important aspects will be elucidated in the procurement of right lobe liver donor graft as it goes to ensure that implantation in recipient are a success with good outcomes.

Attention should be paid to ensure minimal insult to the bile ducts during donor hepatectomy, as it is usually the recipient who bears the brunt of biliary complication after transplantation. Biliary complication such as bile leak and more commonly biliary strictures are encountered in recipient after LT. Although the incidence of bile leak has reduced to $<5 \%$, biliary stricture remained the Achilles' heel for most transplant surgeon as incidence remained high at $15-30 \% .{ }^{[25,26]}$

Thus, various steps are practiced to ensure the insults to bile duct are kept to a minimal during donor operation. The use of real-time operative cholangiogram is mandatory in our center as it helps to accurately identify biliary anatomy, bile duct anomaly, and small ducts that may have been missed if reliance only on radiological imaging is carried out. ${ }^{[27,28]}$ The use of endoscopic retrograde cholangio-pancreatography (ERCP) or percutaneous transhepatic cholangiogram (PTC) is too invasive for healthy donors and not recommended, and the use of magnetic resonance cholangio-pancreatography (MRCP) may miss small ducts as some studies have shown. ${ }^{[28,29]}$

Other consideration to minimize insults to bile duct include avoidance of denuding the bile duct, ensuring the vascular supply around the duct is not disrupted and prevention of clamping on the bile duct during surgery and back table procedure. ${ }^{[25,30,31]}$

With regards to the venous drainage, an adequate venous outflow seen in recipient ensures good graft function. The incorporation of middle hepatic vein (MHV) into the 
right liver lobe graft for a continuous uniform drainage of segment 5 and 8 has been a standard practice in our center and fear of donor safety is allayed from various study. ${ }^{[32,33]}$ Preservation of the segment $4 \mathrm{~b}$ hepatic vein for the remnant left liver of the donor is desirable for venous outflow of segment $4 .{ }^{[34]}$ The right hepatic vein (RHV) and MHV are reconstructed at the back table into a triangular opening to ensure that graft outflow is good before implantation in the recipient. ${ }^{[35]}$

Shortening the cold ischemic time for donor graft also ensures good graft function in recipient. The donor graft is not delivered until the recipient is almost ready for graft implantation and hence, it is imperative that communication between the donor and recipient team takes place. Once donor graft is delivered, flushing of graft takes place at the back table with either University of Wisconsin (UW) solution or histidine-tryptophan-ketoglutarate (HTK) solution. Recent meta-analyses revealed both preservation solutions are comparable and did not show superiority over one another. ${ }^{[36]}$

\section{Recipient hepatectomy}

In preparation for implantation of donor graft, the transplant surgeon are faced with the aspect of technical challenge and difficulty in removing the diseased liver as oftentimes surgery is complicated by extensive venous collaterals or varices from marked portal hypertension, bleeding potential from coagulopathy or thrombocytopenia, a friable liver and thrombosis of the portal vein. Sometimes, abdominal adhesions may complicate surgery as recipient may have previous history of spontaneous bacterial peritonitis or past history of abdominal surgery. ${ }^{[37]}$ In addition, good anesthetic preparation in anticipation for potential difficult surgery is vital and ensuring adequate vascular access, availability of cross-matched blood, and antimicrobial prophylaxis.

The recipient is positioned similar to donor on the operating table. Good exposure is achieved with bilateral subcostal incision and upper midline extension and spread open with a Bookwalter retractor (Codman and Shurtleff, Inc., Raynham, MA, USA). Ascitic fluid obtained is sent for culture and if negative, a cell saver is used to promote autologous and reduce allogeneic blood transfusion but its use is contraindicated if transplantation involved a case of hepatocellular carcinoma. ${ }^{[38,39]}$

Liver is subsequently mobilized and ligamentous attachment is released to gain access to inferior vena cava (IVC), which may allow a sling or vascular clamps to be placed in the supra- and infra-hepatic IVC for control when explanting the diseased liver and implanting of donor graft.
Next, perihilar dissection is performed and unlike donor hepatectomy, dissection is initiated near the hilar plate starting from the right of the common bile duct. At this juncture, we cannot further stress that tissue handling is of utmost importance as vital structures such as bile duct, hepatic artery (HA), and portal vein are encountered and crushing of these structures with instruments should be avoided. Judicious and minimal use of electrocautery or energy source is best advised and lymphatics or vessels are divided between ligatures.

Dissection near bile duct needs extra precaution to prevent denudation of bile duct and avoid severing its blood supply as this may lead to subsequent ischemia and biliary stricture. Minimal dissection has been shown to reduce biliary stricture and techniques such as encircling of the hilar plate can also ensure periductal blood supply is preserved. ${ }^{[31,40,41]}$

One should also take into account that recipient portal vein can be pathological and can present further challenge to the transplant surgeon. Portal vein thrombosis (PVT) is often encountered, especially when cirrhosis is present. In recent times, PVT should no longer be a contraindication to LT. ${ }^{[42,43]}$ A good preoperative work-up and imaging may help identify the extent of PVT and hence, may help surgeons with the appropriate surgical planning and strategy to be employed during surgery. ${ }^{[44,45]}$ Unfortunately, it is not the scope of this article to further explore the various surgical strategy employed in LT for the various grades of PVT.

Once the bile duct, HA, portal vein, and hepatic veins from the IVC are identified and slung, then, the recipient liver is ready to be explanted. Sharp transection with scissors is used for the bile duct, artery and portal vein, and the hepatic veins are transected with vascular stapler where we use the ETS Flex $35 \mathrm{~mm}$ linear cutter (Ethicon Endo-Surgery, Inc., Cincinnati, OH, USA).

\section{Implantation with venous and arterial reconstruction Graft hepatic vein to inferior vena cava}

This is the first step of implantation of the right liver lobe graft where a venoplasty incorporating the RHV and MHV into a single triangular channel was performed at back table procedure. The recipient IVC with supra- and infra-hepatic control applied, is also cut in a triangular fashion, which mirrors that of the donor graft usually at the origin of the recipient's RHV for anastomosis. A suspensory suture is placed at the apex of both the triangular opening and anastomosis began with continuous $5 / 0$ prolene and ends with a growth factor applied. The anastomosis is flushed with heparin saline during the procedure.

Occasionally, one may encounter a right inferior hepatic vein (RIHV) and this may present further challenge to 
the transplant surgeon. We performed anastomosis with continuous prolene $6 / 0$ with growth factor at the end of anastomosis after measuring the size of the RIHV and similar diameter is cut on the mirrored surfaced of the IVC. Ikegami et al. have reported similar technical challenge and use of autogenous vein graft is employed with ease in their series. ${ }^{[46]}$

It is worth mentioning that veno-venous bypass is not commonly practiced in our center as it carries some morbidity along with it and hence should be avoided. ${ }^{[4]}$

Other options practiced in other centers in venous outflow reconstruction include anastomosis to IVC with donor graft that has MHV reconstruction performed with native vein graft (e.g., saphenous vein or internal iliac vein), cryopreserved graft, or prosthetic graft (e.g., PTFE) for segment V5 and V8 venous drainage of the right anterior section where the origin of the MHV was not taken. ${ }^{[48-50]}$ Such reconstruction can be more technically challenging and the use of prosthetic graft may be associated with some morbidity. ${ }^{[51]}$

\section{Graft to native portal vein}

After venous outflow reconstruction, the portal vein is anastomosed next. With the native main portal vein clamp with a Blalock clamp proximally, the native main portal is brought close to the graft portal vein. Any redundant or excess length native portal vein is excised and trimmed in order to avoid kinking of the portal vein, which if not addressed early, may affect venous inflow to the graft. Anastomosis is performed with prolene $6 / 0$ in a continuous fashion over the anterior and posterior wall with growth factor about $2 / 3^{\text {rd }}$ the of portal vein diameter applied at the end of anastomosis. The vein is flushed with heparin saline and proximal release is performed to flush out any potential thrombus before releasing the vascular clamp on the donor graft.

As mentioned earlier, sometimes PVT are encountered and various steps can be performed to overcome this such as a simple thrombectomy, eversion thromboendovenectomy, use of interposition graft, or more complex procedures requiring techniques such as renoportal anastomosis or portal vein arterialization. ${ }^{[52]}$ If severe PVT is encountered, a multivisceral transplant is sometimes warranted but this would have been decided preoperatively. ${ }^{[53]}$

Another challenge faced is portal hypertension or portal over perfusion where deleterious effect can affect a partial graft after transplantation. ${ }^{[54]}$ We have shown that our technique of RHV and MHV venoplasty can lower recipient portal pressure by unimpeded venous outflow and hence, prevent SFSS despite adequate graft size. ${ }^{[5]}$ Modulating over perfusion of portal flow by ligation of the splenic artery also lowers the portal pressure and minimizes the chance of developing SFSS. ${ }^{[56]}$

\section{Arterial anastomosis}

Arterial anastomosis entails the last step of vascular anastomosis for implantation. Important care and steps should also be observed especially in partial liver graft in LDLT as arterial diameter is small and reconstruction of the HA is highly technical and demanding. ${ }^{[57]}$ In the past, reported incidence of arterial complication such as stenosis or thrombosis is high leading to graft failure but recent practice and technical advances have kept this incidence low with a reported incidence of $2-6 \% \cdot{ }^{[57-59]}$

In our center, HA reconstruction is performed under microscope and we have reported a low incidence of arterial complication after such maneuver ${ }^{[58]}$ Fine sutures such as prolene $9 / 0$ are used and anastomosed in an interrupted fashion under microscopy. On table, Doppler ultrasonography (US) is performed immediately after anastomosis to ensure good patency and performed again after abdominal closure. This allows for immediate measures to be taken if any abnormality is detected. Recipient also have regular bedside Doppler US postoperatively once to twice daily to ensure patency remains.

One has to bear in mind that recipient's artery may be unsuitable for anastomosis especially in cases where recipients have undergone transarterial chemoembolization as part of bridging therapy for hepatocellular carcinoma prior to transplantation. Here, gastroduodenal artery (GDA) can be considered as an alternative for arterial reconstruction and hence, understanding the anatomy of arterial network is vital. Use of right gastroepiploic artery (RGEA) has also been reported. ${ }^{\left[{ }^{[0]}\right]}$ The use of this non-HA for anastomosis to graft artery is otherwise known as extra-anatomical HA reconstruction. Besides GDA and RGEA, reported use of right gastric artery, left gastric artery, splenic artery, cystic artery, and interposition graft have been reported and deemed safe with comparable outcome as using anatomical HA. ${ }^{[61]}$

Besides the use of microscope for arterial reconstruction, recent literature have shown that the use of surgical loupes for arterial reconstruction have comparable outcomes as microscope with the added advantage of reduction of operation time and some centers also showed reduction in blood loss and hospital stay. ${ }^{[59,62]}$ This could possibly be attributed to advanced in surgical techniques and improve learning curve gained from years of transplant experience in these centers.

\section{Bile duct reconstruction}

Biliary reconstruction entails the final step of implantation. Measures are taken in order to avoid biliary complication such as bile leak or stricture when undertaking reconstruction. 
Our preference for biliary reconstruction involve duct-to-duct (DD) anastomosis technique, thus it is vital that ductal integrity which often goes hand in hand with its vascular supply are maintained during donor graft surgery and recipient hepatectomy, which is mentioned in earlier part of the article.

DD reconstruction also helps to reduce operating time and contamination from bowel content following enterotomy if hepaticojejunostomy $(\mathrm{HJ})$ is performed as part of reconstruction. However, type of reconstruction should be individualized, as DD reconstruction may not be suitable if the recipient's bile duct is diseased in the case of primary sclerosing cholangitis where $\mathrm{HJ}$ would be preferred. There is no significant difference of biliary complication rate if either DD or $\mathrm{HJ}$ is chosen in our series. ${ }^{\left[{ }^{[3]}\right.} \mathrm{A}$ meta-analysis and systemic review by Zhang et al. also revealed no clear evidence in favor of either DD or HJ. ${ }^{[64]}$ There are also some centers that use microsurgical technique for biliary reconstruction in their practice with low rates of biliary complication reported. ${ }^{[65]}$

For DD reconstruction, it is important that good approximation is achieved, anastomosis is tension-free and blood supply around bile duct is not denuded. We use polydioxanone 6/0 sutures for our DD reconstruction where the posterior wall is sutured with continuous running sutures and anterior wall with interrupted sutures are tied at the end of placement. We do not recommend any placement of biliary stents or T-tube as part of reconstruction.

Other important factors that need consideration during biliary reconstruction that the transplant surgeon needs to observe are (i) ensuring that there is no bile duct stones in recipient which may require choledochoscopy intraoperatively; (ii) size discrepancy between donor and recipient duct; and (iii) the challenge of ductal anomaly of the donor graft, which may present with $>1$ ductal opening. These technical challenges will not be discussed in detail here.

All in all, one should remember that the techniques of biliary reconstruction should be individualized and adapted depending on the biliary anatomy of both donor and recipient.

\section{CONCLUSION}

Adult-to-adult LDLT is widely accepted today with safe and good outcome reported worldwide for both donor and recipient. Our experience with right lobe liver graft ensures that graft size limitation is overcome in adult-to-adult LDLT. Ensuring graft success is multifactorial even at the preoperative planning stage and understanding the intraoperative technical challenges that comes along with it as well as the physiology of flow modulation. One needs to arm oneself with all the possible knowledge in overcoming these technical challenges and the ability to be flexible and adaptable during LDLT by tailoring the needs of each patient individually.

\section{Financial support and sponsorship}

Nil.

\section{Conflicts of interest}

There are no conflicts of interest.

\section{REFERENCES}

1. Starzl TE, Marchioro TL, Vonkaulla KN, Hermann G, Brittain RS, Waddell WR. Homotransplantation of the liver in humans. Surg Gynecol Obstet 1963;117:659-76.

2. Chan SC, Fan ST, Lo CM, Liu CL, Wong J. Toward current standards of donor right hepatectomy for adult-to-adult live donor liver transplantation through the experience of 200 cases. Ann Surg 2007;245:110-7.

3. Liu CL, Lam B, Lo CM, Fan ST. Impact of right-lobe live donor liver transplantation on patients waiting for liver transplantation. Liver Transpl 2003;9:863-9.

4. Zink S, Weinreib R, Sparling T, Caplan AL. Living donation: Focus on public concerns. Clin Transplant 2005;19:581-5.

5. Abecassis M, Adams M, Adams P, Arnold RM, Atkins CR, Barr ML, et al. Consensus statement on the live organ donor. JAMA 2000;284:2919-26.

6. Barr ML, Belghiti J, Villamil FG, Pomfret EA, Sutherland DS, Gruessner RW, et al. A report of the Vancouver Forum on the care of the live organ donor: Lung, liver, pancreas, and intestine data and medical guidelines. Transplantation 2006;81:1373-85.

7. Shi ZR, Yan LN, Du CY. Donor safety and remnant liver volume in living donor liver transplantation. World J Gastroenterol 2012;18:7327-32.

8. Chan SC, Fan ST, Lo CM, Liu CL, Wei WI, Chik BH, et al. A decade of right liver adult-to-adult living donor liver transplantation: The recipient mid-term outcomes. Ann Surg 2008;248:411-9.

9. Lo CM, Fan ST, Liu CL, Lo RJ, Lau GK, Wei WI, et al. Extending the limit on the size of adult recipient in living donor liver transplantation using extended right lobe graft. Transplantation 1997;63:1524-8.

10. Kim JD, Choi DL, Han YS. Simplified one-orifice venoplasty for middle hepatic vein reconstruction in adult living donor liver transplantation using right lobe grafts. Clin Transplant 2014;28:561-8.

11. Malagó M, Testa G, Frilling A, Nadalin S, Valentin-Gamazo C, Paul A, et al. Right living donor liver transplantation: An option for adult patients: Single institution experience with 74 patients. Ann Surg 2003;238:853-62.

12. Surman OS. Psychiatric aspects of liver transplantation. Psychosomatics 1994;35:297-307.

13. Crone CC, Wise TN. Psychiatric aspects of transplantation, II: Preoperative issues. Crit Care Nurse 1999;19:51-63.

14. Crone CC, Wise TN. Psychiatric aspects of transplantation, III: Postoperative issues. Crit Care Nurse 1999;19:28-38.

15. Crone CC, Wise TN. Psychiatric aspects of transplantation, I: Evaluation and selection of candidates. Crit Care Nurse 1999;19:79-87.

16. Segatto BL, Sabiston CM, Harvey WJ, Bloom GA. Exploring relationships among distress, psychological growth, motivation, and physical activity among transplant recipients. Disabil Rehabil 2013;35:2097-103.

17. Lo CM, Fan ST, Chan JK, Wei W, Lo RJ, Lai CL. Minimum graft volume for successful adult-to-adult living donor liver transplantation for fulminant hepatic failure. Transplantation 1996;62:696-8. 
Koh and Chan: Adult-to-adult LDLT

18. Dahm F, Georgiev P, Clavien PA. Small-for-size syndrome after partial liver transplantation: Definition, mechanisms of disease and clinical implications. Am J Transplant 2005;5:2605-10.

19. Lee SD, Kim SH, Kim YK, Lee SA, Park SJ. Graft-to-recipient weight ratio lower to $0.7 \%$ is safe without portal pressure modulation in right-lobe living donor liver transplantation with favorable conditions. Hepatobiliary Pancreat Dis Int 2014;13:18-24.

20. Chan SC, Liu CL, Lo CM, Lam BK, Lee EW, Wong Y, et al. Estimating liver weight of adults by body weight and gender. World J Gastroenterol 2006;12:2217-22.

21. Ben-Haim M, Emre S, Fishbein TM, Sheiner PA, Bodian CA, Kim-Schluger $\mathrm{L}$, et al. Critical graft size in adult-to-adult living donor liver transplantation: Impact of the recipient's disease. Liver Transpl 2001;7:948-53.

22. Lee S, Park K, Hwang S, Lee Y, Choi D, Kim K, et al. Congestion of right liver graft in living donor liver transplantation. Transplantation 2001;71:812-4.

23. Marcos A, Orloff M, Mieles L, Olzinski AT, Renz JF, Sitzmann JV. Functional venous anatomy for right-lobe grafting and techniques to optimize outflow. Liver Transpl 2001;7:845-52.

24. Man K, Lo CM, Ng IO, Wong YC, Qin LF, Fan ST, et al. Liver transplantation in rats using small-for-size grafts: A study of hemodynamic and morphological changes. Arch Surg 2001;136:280-5.

25. Chok KS, Lo CM. Prevention and management of biliary anastomotic stricture in right-lobe living-donor liver transplantation. J Gastroenterol Hepatol 2014;29:1756-63.

26. Chok KS, Chan SC, Cheung TT, Sharr WW, Chan AC, Lo CM, et al. Bile duct anastomotic stricture after adult-to-adult right lobe living donor liver transplantation. Liver Transpl 2011;17:47-52.

27. Chan SC, Fan ST. Biliary complications in liver transplantation. Hepatol Int 2008;2:399-404.

28. Gao F, Xu X, Zhu YB, Wei Q, Zhou B, Shen XY, et al. Impact of intra-operative cholangiography and parenchymal resection to donor liver function in living donor liver transplantation. Hepatobiliary Pancreat Dis Int 2014;13:259-63.

29. Hsu HW, Tsang LL, Yap A, Huang TL, Chen TY, Lin TS, et al. Magnetic resonance cholangiography in living donor liver transplantation. Transplantation 2011;92:94-9.

30. Gunji H, Cho A, Tohma T, Okazumi S, Makino H, Shuto K, et al. The blood supply of the hilar bile duct and its relationship to the communicating arcade located between the right and left hepatic arteries. Am J Surg 2006;192:276-80.

31. Fan ST, Lo CM, Liu CL. Technical refinement in adult-to-adult living donor liver transplantation using right lobe graft. Ann Surg 2000;231:126-31.

32. Scatton O, Belghiti J, Dondero F, Goere D, Sommacale D, Plasse M, et al. Harvesting the middle hepatic vein with a right hepatectomy does not increase the risk for the donor. Liver Transpl 2004;10:71-6.

33. de Villa VH, Chen CL, Chen YS, Wang CC, Lin CC, Cheng YF, et al. Right lobe living donor liver transplantation-addressing the middle hepatic vein controversy. Ann Surg 2003;238:275-82.

34. Chan SC, Lo CM, Liu CL, Wong Y, Fan ST, Wong J. Tailoring donor hepatectomy per segment 4 venous drainage in right lobe live donor liver transplantation. Liver Transpl 2004;10:755-62.

35. Lo CM, Fan ST, Liu CL, Wong J. Hepatic venoplasty in living-donor liver transplantation using right lobe graft with middle hepatic vein. Transplantation 2003;75:358-60.

36. O'Callaghan JM, Morgan RD, Knight SR, Morris PJ. The effect of preservation solutions for storage of liver allografts on transplant outcomes: A systematic review and meta-analysis. Ann Surg 2014;260:46-55.

37. Conzen KD, Majella-Doyle MB, Chapman WC. Orthotopic liver transplantation. In: Jarnagin WR, editor. Blumgart's Surgery of the Liver, Biliary Tract and Pancreas. $5^{\text {th }}$ ed., Vol. 2. USA: Elsevier; 2012. p. $1722-36$

38. Feltracco P, Brezzi M, Barbieri S, Galligioni H, Milevoj M, Carollo C, et al. Blood loss, predictors of bleeding, transfusion practice and strategies of blood cell salvaging during liver transplantation. World J Hepatol 2013;5:1-15.

39. Zhai B, Sun XY. Controversy over the use of intraoperative blood salvage autotransfusion during liver transplantation for hepatocellular carcinoma patients. World J Gastroenterol 2013;19:3371-4

40. Ikegami T, Shirabe K, Morita K, Soejima Y, Taketomi A, Yoshizumi T, et al. Minimal hilar dissection prevents biliary anastomotic stricture after living donor liver transplantation. Transplantation 2011;92:1147-51.

41. Takatsuki M, Eguchi S, Tokai H, Hidaka M, Soyama A, Tajima Y, et al. A secured technique for bile duct division during living donor right hepatectomy. Liver Transpl 2006;12:1435-6.

42. Yerdel MA, Gunson B, Mirza D, Karayalçin K, Olliff S, Buckels J, et al. Portal vein thrombosis in adults undergoing liver transplantation: Risk factors, screening, management, and outcome. Transplantation 2000;69:1873-81.

43. Francoz C, Valla D, Durand F. Portal vein thrombosis, cirrhosis, and liver transplantation. J Hepatol 2012;57:203-12.

44. John BV, Konjeti R, Aggarwal A, Lopez R, Atreja A, Miller C, et al. Impact of untreated portal vein thrombosis on pre and post liver transplant outcomes in cirrhosis. Ann Hepatol 2013;12:952-8.

45. Germanova D, Lucidi V, Buggenhout A, Boon N, Bourgeois N, Degré $\mathrm{D}$, et al. Liver transplantation in cases of portal vein thrombosis in the recipient: A case report and review of the various options. Transplant Proc 2011;43:3490-2.

46. Ikegami T, Shirabe K, Yoshiya S, Soejima Y, Yoshizumi T, Uchiyama H, et al. One-step reconstruction of the right inferior hepatic veins using auto-venous grafts in living-donor liver transplantation. Surg Today 2013;43:769-76.

47. Fan ST, Yong BH, Lo CM, Liu CL, Wong J. Right lobe living donor liver transplantation with or without venovenous bypass. Br J Surg 2003;90:48-56.

48. Sugawara Y, Makuuchi M, Sano K, Imamura H, Kaneko J, Ohkubo T, et al. Vein reconstruction in modified right liver graft for living donor liver transplantation. Ann Surg 2003;237:180-5.

49. Lee SG. Techniques of reconstruction of hepatic veins in living-donor liver transplantation, especially for right hepatic vein and major short hepatic veins of right-lobe graft. J Hepatobiliary Pancreat Surg 2006;13:131-8.

50. Yi NJ, Suh KS, Lee HW, Cho EH, Shin WY, Cho JY, et al. An artificial vascular graft is a useful interpositional material for drainage of the right anterior section in living donor liver transplantation. Liver Transpl 2007;13:1159-67.

51. Ha TY, Hwang S, Jung DH, Ahn CS, Kim KH, Moon DB, et al. Complications analysis of polytetrafluoroethylene grafts used for middle hepatic vein reconstruction in living-donor liver transplantation. Transplant Proc 2014;46:845-9.

52. Pécora RA, Canedo BF, Andraus W, Martino RB, Santos VR, Arantes RM, et al. Portal vein thrombosis in liver transplantation. Arq Bras Cir Dig 2012;25:273-8.

53. Vianna RM, Mangus RS, Tector AJ. Current status of small bowel and multivisceral transplantation. Adv Surg 2008;42:129-50.

54. Troisi R, Cammu G, Militerno G, De Baerdemaeker L, Decruyenaere J, Hoste E, et al. Modulation of portal graft inflow: A necessity in adult living-donor liver transplantation? Ann Surg 2003;237:429-36.

55. Chan SC, Lo CM, Ng KK, Ng IO, Yong BH, Fan ST. Portal inflow and pressure changes in right liver living donor liver transplantation including the middle hepatic vein. Liver Transpl 2011;17:115-21.

56. Lo CM, Liu CL, Fan ST. Portal hyperperfusion injury as the cause of primary nonfunction in a small-for-size liver graft-successful treatment with splenic artery ligation. Liver Transpl 2003;9:626-8.

57. Iida T, Kaido T, Yagi S, Hori T, Uchida Y, Jobara K, et al. Hepatic arterial complications in adult living donor liver transplant recipients: A single-center experience of 673 cases. Clin Transplant 2014;28:1025-30.

58. Wei WI, Lam LK, Ng RW, Liu CL, Lo CM, Fan ST, et al. Microvascular reconstruction of the hepatic artery in live donor liver transplantation: Experience across a decade. Arch Surg 2004;139:304-7.

59. Marubashi S, Kobayashi S, Wada H, Kawamoto K, Eguchi H, Doki Y, et al. Hepatic artery reconstruction in living donor liver transplantation: Risk factor analysis of complication and a role of MDCT scan for detecting anastomotic stricture. World J Surg 2013;37:2671-7.

60. Lee JH, Oh DY, Seo JW, Moon SH, Rhie JW, Ahn ST. Versatility of right gastroepiploic and gastroduodenal arteries for arterial 


\section{Koh and Chan: Adult-to-adult LDLT}

reconstruction in adult living donor liver transplantation. Transplant Proc 2011;43:1716-9.

61. Uchiyama H, Shirabe K, Taketomi A, Soejima Y, Ninomiya M, Kayashima $\mathrm{H}$, et al. Extra-anatomical hepatic artery reconstruction in living donor liver transplantation: Can this procedure save hepatic grafts? Liver Transpl 2010;16:1054-61.

62. Yagi T, Shinoura S, Umeda Y, Sato D, Yoshida R, Yoshida K, et al. Surgical rationalization of living donor liver transplantation by abolition of hepatic artery reconstruction under a fixed microscope. Clin Transplant 2012;26:877-83.
63. Liu CL, Lo CM, Chan SC, Fan ST. Safety of duct-to-duct biliary reconstruction in right-lobe live-donor liver transplantation without biliary drainage. Transplantation 2004;77:726-32.

64. Zhang S, Zhang M, Xia Q, Zhang JJ. Biliary reconstruction and complications in adult living donor liver transplantation: Systematic review and meta-analysis. Transplant Proc 2014;46:208-15.

65. Lin TS, Chen CL, Concejero AM, Yap AQ, Lin YH, Liu CY, et al. Section 9. Technical details of microsurgical biliary reconstruction in living donor liver transplantation. Transplantation 2014;97 Suppl 8:S34-6. 